\title{
Density dependence of the alarm pheromone effect in pea aphids, Acyrthosiphon pisum (Sternorrhyncha: Aphididae)
}

\author{
GRIT KUNERT*, JANETt TRAUTSCH and WolFGANG W. WEISSER
}

Institute of Ecology, Friedrich-Schiller-Universität, Dornburger Str. 159, 07743 Jena, Germany

\begin{abstract}
Key words. Alarm pheromone, predator-prey interactions, population dynamics, aphid wing polyphenism, Aphididae, Acyrthosiphon pisum, density effects, wing induction
\end{abstract}

\begin{abstract}
The aphid alarm pheromone is known to trigger wing induction in pea aphids (Acyrthosiphon pisum). In reaction to alarm pheromone, aphids drop off the plant or walk away. While searching for a new feeding site they repeatedly encounter other members of the aphid colony and this increased contact rate is assumed to be important for wing induction ("pseudo-crowding" hypothesis). Because the encounter rate is a function of aphid colony size, wing induction in aphids in the presence of a predator should be a function of the number of aphids on the plant. We placed two, seven or 13 adult pea aphids on bean plants, and exposed the different-sized colonies to synthetic alarm pheromone to test the density-dependence of predator-induced wing induction. The mean percentage of winged morphs among the offspring produced on the plants ranged from 10 to 80 percent and increased both with aphid number and exposure to alarm pheromone. There was no synergy between aphid number and alarm pheromone exposure indicating that both factors are additive. The implications for aphid metapopulation dynamics are discussed.
\end{abstract}

\section{INTRODUCTION}

Aphids (Sternorrhyncha: Aphididae) are attacked by a wide range of predators such as ladybirds, lacewings and hoverfly larvae, which have been shown to strongly influence the growth and persistence of aphid colonies (Dixon, 1998). Under predator attack, aphids secrete droplets from the siphunculi, a pair of tube-like structures on the back of their bodies. In addition to having direct defensive function by gluing predator mouthparts together, the droplets contain an alarm pheromone whose main and often only component is the sesquiterpene $(E)-\beta$ farnesene, EBF (Bowers et al., 1972; Edwards et al., 1973; Nault et al., 1973; Pickett \& Griffiths, 1980). EBF triggers various behavioural reactions in other aphids such as increased alertness, withdrawal of the stylets from the plant, walking behaviour and dropping off the host plant (Montgomery \& Nault, 1977; Wohlers, 1980). These escape reactions are very efficient in reducing the predation risk of aphids and are an important component of aphid predator-prey interactions (e.g. Minoretti \& Weisser, 2000).

Aphids exhibit a polyphenism whereby individual aphids are either winged or wingless (Dixon, 1998). The winged dispersal morphs mostly leave the plants on which they were born to colonize new plants and, in many species, are only produced in response to adverse environmental conditions such as crowding or poor plant quality. The wingless morphs mostly stay on the plant on which they are born. In the case of crowding, the proximate mechanism for wing induction is the increased number of physical contacts between individuals due to increasing aphid density on the plant (Sutherland, 1969).
Recently, aphid alarm pheromone has been found to be involved in pea aphid (Acyrthosiphon pisum) wing induction caused by natural enemies (Kunert et al., 2005). The mechanism for this wing induction seems to be quite similar to the mechanism that was found to be important for crowding (Fig. 1). Searching for a new feeding site increases the contact rate between aphids as individuals in their search frequently encounter other, feeding or searching, individuals, which then leads to wing induction (Sutherland, 1969). Because only groups of aphids react to alarm pheromone with wing induction but not single aphids (Kunert et al., 2005), alarm pheromone is only an indirect cue for wing induction. This "pseudo-crowding hypothesis" (Sloggett \& Weisser, 2004) is supported by the results of Kunert et al. (2005), who found that the more often the alarm pheromone is applied, the higher is the aphid walking response, and the higher is the percentage of winged offspring.

Because of the dependence of wing induction on contact rate, a dependence of wing induction on aphid density can be postulated. Such dependence would have consequences for aphid predator-prey metapopulation dynamics. In this paper, we test if wing induction due to alarm pheromone exposure is a function of the number of individuals in an aphid colony.

\section{MATERIAL AND METHODS}

This experiment was conducted with the red clone BP of the pea aphid Acyrthosiphon pisum, which has been used earlier (Weisser et al., 1999; Sloggett \& Weisser, 2002; Kunert \& Weisser, 2003, 2005; Kunert et al., 2005). The aphids were reared and the experiment took place under long day conditions (16L : $8 \mathrm{D})$, at $20^{\circ} \mathrm{C}$, and $75 \%$ r.h. Three week old broad bean

\footnotetext{
* Author for correspondence; present address: Max-Planck-Institute for Chemical Ecology, Hans-Knöll-Str. 8, 07745 Jena, Germany; e-mail: gkunert@ice.mpg.de
} 


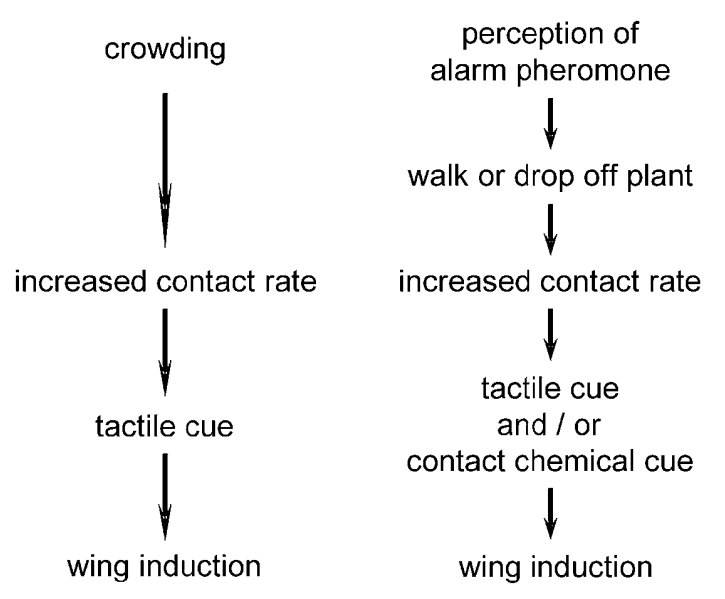

Fig. 1. Comparison of wing induction mechanisms in the case of crowding (left) and attack by natural enemies (right).

plants (Vicia faba) were used as host plants. To prevent the escape of the aphids the plants were enclosed in air-permeable cellophane bags.

15 lines of aphids were reared for this experiment. Each line was used for one replication. To start a line one adult unwinged aphid was placed on a bean plant and allowed to reproduce for two days. Thereafter the adult aphid was removed and the offspring were reared until they became adult. Five of the offspring were then transferred separately to new plants where they reproduced for two days. Each line then consisted of about 50 aphids. These aphids were reared to the third or fourth larval instar and then separated into three densities consisting of two, seven or 13 adult aphids. These densities were chosen to cover the range between one aphid and 15 aphids, which were used previously in wing induction experiments (Kunert et al., 2005). Each density category consisted of an alarm pheromone treatment with EBF and a control. In the EBF treatments, 50ng EBF dissolved in n-hexane was applied three times a day (morning, noon, evening). Only the solvent $n$-hexane was applied in the controls. EBF and n-hexane were applied on a piece of filter paper fixed on a wooden tooth pick at the bottom of the plant. The application of EBF and n-hexane was carried out for five days during which time the aphids became adults and started to reproduce.

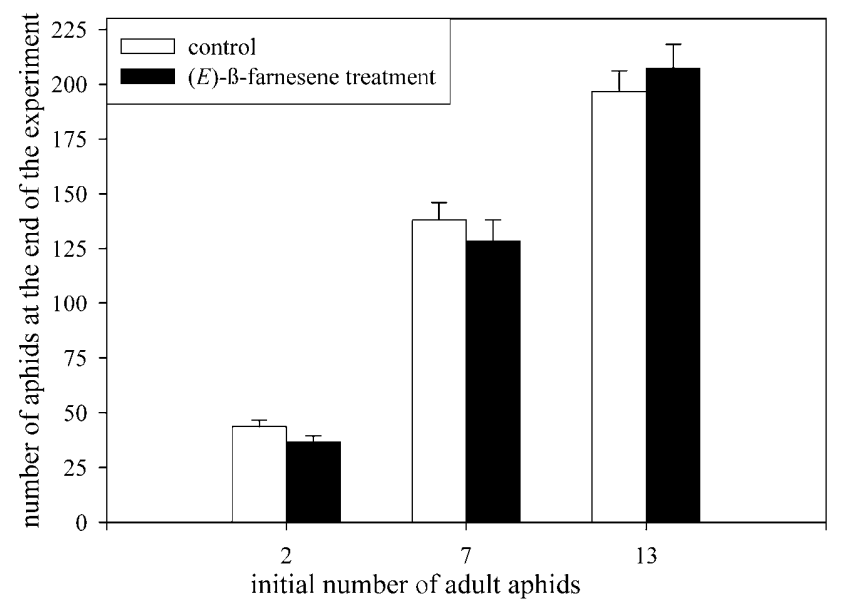

Fig. 2. Dependence of aphid colony size on initial adult aphid number $(\mathrm{F}=287.023, \mathrm{p}<0.001)$ and alarm pheromone treatment $(\mathrm{F}=0.674, \mathrm{p}=0.414)$.
After five days, the adult aphids were removed from the plant and the offspring reared until they reached the fourth larval or adult stage. Then they were removed from the plant and frozen for later counting and morph determination.

To analyse whether the density treatments were successful, the numbers of aphids at the end of the experiment were compared using a two-way ANOVA. The Tukey post-hoc test was used to isolate which groups differ from the others in a multiple comparison procedure (SigmaStat for Windows version 2.03). Since the data did not have equal variances they were square root transformed.

The influence of EBF application and aphid number on aphid wing induction was tested with a general linear model using the software package R 2.0.1 (Crawley, 2002; Venables et al., 2002).

\section{RESULTS}

\section{Number of aphids at the end of the experiment}

The number of aphids at the end of the experiment depended on the initial number of adult aphids present on the plant $(\mathrm{F}=287.023, \mathrm{p}<0.001$; Fig. 2). The three treatments differed significantly in the mean number of aphids at the end of the experiment, and final aphid number strongly increased with initial aphid number (treatment 2 vs. $7: \mathrm{q}=21.94, \mathrm{p}<0.001 ; 2$ vs. $13: \mathrm{q}=33.33, \mathrm{p}<0.001$; 7 vs. 13: $\mathrm{q}=11.39, \mathrm{p}<0.001)$.

The application of EBF did not significantly influence aphid number at the end of the experiment $(\mathrm{F}=0.674, \mathrm{p}=$ 0.414; Fig. 2). Similarly, the interaction between the EBF application and the initial number of aphids was not significant $(\mathrm{F}=1.137, \mathrm{p}=0.326)$.

\section{Percentage of winged offspring}

The percentage of winged offspring was significantly influenced both by the application of EBF $(t=9.290, p<$ $0.001)$ and by the initial number of aphids $(t=4.675, p<$ $0.001)$. There was no interaction between the application of EBF and the aphid number $(t=0.683, p=0.496$; Fig. 3).

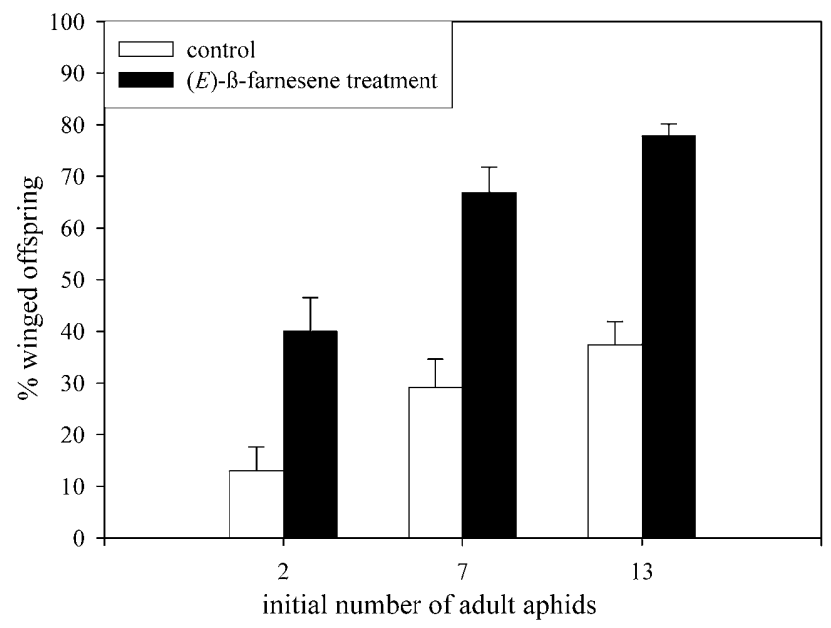

Fig. 3. Dependence of mean percentage of winged offspring on initial adult aphid number $(\mathrm{t}=4.675, \mathrm{p}<0.001)$ and alarm pheromone treatment $(\mathrm{t}=9.290, \mathrm{p}<0.001)$. 


\section{DISCUSSION}

Our results confirm the findings of prior experiments that exposure of pea aphid colonies to EBF leads to a higher percentage of winged offspring compared to the controls (Kunert et al., 2005). Because there was no influence of EBF on the number of offspring produced, which only depended on the initial number of adult aphids, the aphid number at the end of the experiment was the only parameter that differed between the density categories. Thus, our findings corroborate the "crowding" hypothesis (Sloggett \& Weisser, 2004) that an increased contact rate due to agitation in response to EBF leads to a higher percentage of winged offspring in the same way as it does for normal crowding. The disturbance of the aphids, however, does not happen only through direct confrontation with natural enemies but also by the perception of the alarm pheromone, which then starts the cascade that leads finally to wing induction. Another cue, known to be important for wing formation, is the nutrition of the aphids (Harrewijn, 1978). However in our study this should be of minor importance since all host plants were of the same age and nutritional status. Also feeding interruption, which occurs when aphids were disturbed by predators or by the perception of EBF, has no influence on wing induction in pea aphids (Sloggett \& Weisser, 2004).

Aphid number was a crucial factor in the experiment as the mean proportion of winged offspring increased with increasing aphid number, both in the control and the alarm pheromone treatment. Interestingly, over the range of aphid densities investigated, the effects of alarm pheromone treatment and aphid number were additive. Thus, even when aphid number was low there was a clear effect of EBF exposure on wing induction and this was also true at the highest aphid number. These results allow an interpretation of the findings of Kunert \& Weisser (2003) who found that the wing induction effect of foraging lacewing and hoverfly larvae was low when very few or very many aphids were consumed, and high when an intermediate number of aphids were consumed. In these experiments the initial number of aphids on the plants was fixed. In the light of the present results the findings can be explained as follows: high predation rates imply a high frequency of alarm pheromone releases, which generally increases the proportion of winged morphs among offspring. In contrast, a low predation rate decreases contact rate and hence decreases wing induction. These general trends are modified by the initial number of aphids on the plant: if the initial number of aphids is low and predation rate is so high that only few aphids remain, the effect of the alarm pheromone will be reduced because the remaining aphids will meet rarely when walking on the plant. On the other hand, a moderate or even low predation rate may still lead to high wing induction if the remaining aphid number is high enough for a high contact rate. A very low predation rate may, however, lead to almost no effect on wing induction even at high aphid densities if the rate of EBF emission remains very low. The interaction between aphid number and predation rate is interesting as it shows that it is not predation or aphid number alone that determines the dispersal rate of aphid colonies. In the present experiment, where initial aphid number was manipulated, increasing the initial number of adult pea aphids from two to 13 aphids had the same effect on wing induction as applying EBF to these small colonies. Dawson et al. (1987) found that in the turnip aphid, Lipaphis (Hyadaphis) erysimi, the effect of EBF, which is one of the main components of the alarm pheromone, is increased by plant-derived isothiocyanates. These plant-derived synergists of alarm pheromone can be released in higher concentrations at higher aphid densities. In our system there is no evidence for plant-derived synergists or antagonists of EBF (Kunert et al., 2005) but the possibility of density-dependent effects in the amount of EBF released by individual aphids is intriguing and has not been tested so far.

Our results may have implications for our understanding of aphid-natural enemy metapopulation dynamics. In the experiments, there was a clear increase in winged morphs even at low aphid densities. Thus, in a natural setting where aphid colonies are often small and frequently visited by predators or parasitoids (cf. Weisser, 2000), dispersal rates should be much higher than expected from density effects alone. Incorporating these density and natural enemy effects into aphid-natural enemy population models should elucidate the importance of each factor for dispersal and long-term persistence of the system (e.g. Kidd, 1990; Kindlmann \& Dixon, 1996; Plantegenest \& Kindlmann, 1999). Incorporating these effects into applied models of dispersal, as formulated to forecast future infestations of aphids in fields, may also improve our understanding of the effects of natural enemies on aphids (Taylor, 1977; Bommarco \& Ekbom, 1995; Harrington \& Pickup, 2005).

ACKNOWLEDGEMENTS. We thank I. Jakobi for help with the rearing of plants and animals. This study was funded by grant No. WE 2618/2-2 of the Deutsche Forschungsgemeinschaft (DFG).

\section{REFERENCES}

Bommarco R. \& Еквом B. 1995: Phenology and prediction of pea aphid infestations on peas. Int. J. Pest Manag. 41: 109-113.

Bowers W.S., Webb R.E., Nault L.R. \& Dutky S.R. 1972: Aphid alarm pheromone: Isolation, identification, synthesis. Science 177: 1121-1122.

Crawley M.J. 2002: Statistical Computing. John Wiley \& Sons, West Sussex, ix + 761 pp.

Dawson G.W., Griffiths D.C., Pickett J.A., Wadhams L.J. \& Woodcock C.M. 1987: Plant-derived synergists of alarm pheromone from turnip aphid, Lipaphis (Hyadaphis) erysimi (Homoptera, Aphididae). J. Chem. Ecol. 13: 1663-1671.

Dixon A.F.G. 1998: Aphid Ecology. Chapman \& Hall, London, $300 \mathrm{pp}$.

Edwards L.J., Siddall J.B., Dunham L.L., Uden P. \& Kislow C.J. 1973: Trans-betafarnesene, alarm pheromone of green peach aphid, Myzus persicae (Sulzer). Nature 241: 126-127.

HARREWIJN P. 1978: Role of plant substances in polymorphism of the aphid Myzus persicae. Entomol. Exp. Appl. 24: $398-414$. 
Harrington R. \& Pickup J. 2005: Rothamsted Insect Survey. http://www.rothamsted.bbsrc.ac.uk/insect-survey/.

KIDD N.A.C. 1990: The population dynamics of the large pine aphid, Cinara pinea (Mordv.), I. Simulation of field populations. Res. Pop. Ecol. 32: 209-226.

Kindlmann P. \& Dixon A.F.G. 1996: Population dynamics of a tree-dwelling aphid: Individuals to populations. Ecol. Model. 89: $23-30$.

Kunert G. \& Weisser W.W. 2003: The interplay between density- and trait-mediated effects in predator-prey interactions: a case study in aphid wing polymorphism. Oecologia 135: 304-312.

Kunert G. \& Weisser W.W. 2005: The importance of antennae for pea aphid wing induction in the presence of natural enemies. Bull. Entomol. Res. 95: 125-131.

Kunert G., Otto S., Röse U.S.R., Gershenzon J. \& Weisser W.W. 2005: Alarm pheromone mediates production of winged dispersal morphs in aphids. Ecol. Lett. 8: 596-603.

Minoretti N. \& Weisser W.W. 2000: The impact of individual ladybirds (Coccinella septempunctata, Coleoptera: Coccinellidae) on aphid colonies. Eur. J. Entomol. 97: 475-479.

Montgomery M.E. \& Nault L.R. 1977: Comparative response of aphids to the alarm pheromone, (E)-B- farnesene. Entomol. Exp. Appl. 22: 236-242.

Nault L.R., Edwards L.J. \& Styer W.E. 1973: Aphid alarm pheromones: Secretion and reception. Environ. Entomol. 2: 101-105.

PicketT J.A. \& GRIFfiths D.C. 1980: Composition of aphid alarm pheromones. J. Chem. Ecol. 6: 349-360.
Plantegenest M. \& Kindlmann P. 1999: Evolutionarily stable strategies of migration in heterogeneous environments. Evol. Ecol. 13: 229-244.

Sloggett J.J. \& Weisser W.W. 2002: Parasitoids induce production of the dispersal morph in the pea aphid, Acyrthosiphon pisum. Oikos 98: 323-333.

Sloggett J.J. \& Weisser W.W. 2004: A general mechanism for predator- and parasitoid-induced dispersal in the pea aphid, Acyrthosiphon pisum (Harris). In Hullé M. (ed.): 6th International Symposium on Aphids, 3-7 September 2001, Rennes France. pp 79-85.

SutherLAND O.R.W. 1969: The role of crowding in the production of winged forms by two strains of the pea aphid, Acyrthosiphon pisum. J. Insect Physiol. 15: 1385-1410.

TAYLOR L.R. 1977: Aphid forecasting and the Rothamsted Insect Survey. J. R. Agric. Soc. England 138: 75-97.

Venables W.N., Smith D.M. \& Team R.D.C. 2002: An Introduction to R. Notes on R: A Programming Environment for Data Analysis and Graphics. R Development Core Team. [PDF manual] URL < http://www.r-project.org/>.

WEISSER W.W. 2000: A host-parasitoid metapopulation. Entomol. Exp. Appl. 97: 83-92.

Weisser W.W., Braendle C. \& Minoretti N. 1999: Predatorinduced morphological shift in the pea aphid. Proc. R. Soc. Lond. (B) 266: 1175-1182.

Wohlers P. 1980: Die Fluchtaktion der Erbsenlaus Acyrthosiphon pisum ausgelöst durch Alarmpheromon und zusätzliche Reize. Entomol. Exp. Appl. 27: 156-168.

Received May 12, 2006; revised and accepted August 31, 2006 